\title{
The genus Macrolepiota (Agaricaceae, Basidiomycota) in China
}

\author{
Z. W. Ge $\cdot$ Zhu L. Yang $\cdot$ Else C. Vellinga
}

Received: 21 June 2010 / Accepted: 13 September 2010 / Published online: 30 September 2010

(C) The Author(s) 2010. This article is published with open access at Springerlink.com

\begin{abstract}
Species of the genus Macrolepiota (Agaricaceae) in China were investigated on the basis of morphology and DNA sequences data. Six species, i.e., $M$. detersa, $M$. dolichaula, M. mastoidea, M. orientiexcoriata, M. procera, and $M$. velosa are recognized, of which $M$. detersa and $M$. orientiexcoriata are new species. All of them are described and illustrated with line drawings, and a key is provided to those recognized species. The taxonomic uncertainty of $M$. crustosa, originally described from China, is also discussed. ITS sequences were used to support the new species delimitations and to test the conspecificity between the Chinese specimens and their relatives from other continents. Phylogenetic analyses identify three clades within Macrolepiota: /macrolepiota, /macrosporae, and /volvatae clade. /macrolepiota clade and /macrosporae clade respectively correspond to section Macrolepiota and section Macrosporae in Bon's infrageneric classification. Section Volvatae is proposed to accommodate species with a volva but without clamp connections within Macrolepiota.
\end{abstract}

Keywords Agaricales · Chlorophyllum · Morphology · Systematics · Taxonomy

\footnotetext{
Z. W. Ge $\cdot$ Z. L. Yang $(\bowtie)$

Key Laboratory of Biodiversity and Biogeography, Kunming Institute of Botany, Chinese Academy of Sciences, Kunming 650204, People's Republic of China e-mail: fungi@mail.kib.ac.cn

Z. W. Ge

Harvard University herbaria,

Cambridge 02138 MA, USA

E. C. Vellinga

Department of Plant and Microbial Biology,

University of California,

Berkeley, CA 94720-310, USA
}

\section{Introduction}

The genus Macrolepiota (Agaricaceae, Agaricales, Basidiomycota) was established by Singer (1948). Macroscopically, basidiomata of species in this genus are typically big, fleshy, and often with squamules on the pileus; lamellae are white to cream; a prominent annulus is usually present which is often movable. Microscopically, clamp connections are present on the septa of the hyphae in lamellae; basidiospores are thick-walled, relatively big, white to cream when accumulated, and the inner spore-wall is metachromatic in cresyl blue (Singer 1948).

Originally, Macrolepiota only accommodated nonvolvate species. Species with a well-formed cup-like volva were placed in a separate genus, namely Volvolepiota Singer (Singer 1959). A recent study indicated that a volva at the base of the stipe does not warrant a separate genus, and thus, Volvolepiota is synonymous with Macrolepiota (Vellinga and Yang 2003). Accordingly, the genus Macrolepiota in the current sense also contains species with a cup-like volva.

Based on morphological and molecular data, Johnson (1999) investigated the traditional classification of the lightspored Lepiota s.1., and found Macrolepiota is not monophyletic. Later on, Vellinga et al. (2003) evaluated the generic level of Macrolepiota, which was shown to be a monophyletic genus after transferring species with pileal squamules made up of a hymenidermal layer, spores with truncated germ pore or without a germ pore, and a smooth stipe to Chlorophyllum Massee. Consequently, representatives of Macrolepiota in the present sense are characterized by the combination of the following characters: pileal squamules of a trichodermal layer made up of long subcylindric elements, spores with a germ pore caused by an interruption of the episporium covered by a hyalinous 
cap, and the presence of stipe squamules, often visible as colored bands in the full-grown specimens (Vellinga 2003 Vellinga et al. 2003).

Currently, there are about 30 species recognized world wide (Kirk et al. 2008). Although the genus contains some edible species, which have been an interest to cultivate by researchers (e.g. Ding and Huang 2003), knowledge of this genus in East Asia is poor and fragmentary. Although a few species of Macrolepiota were recorded from China (Shao and Xiang 1981; Zang et al. 1996; Bi et al. 1997; Mao 2000; Teng 1996; Vellinga and Yang 2003), literature on some of these records has very limited information in the descriptions, and information on voucher specimens is lacking (e.g. Mao 2000, 2009; Teng 1996). Based on extensive morphological examination and molecular phylogenetic analyses, species diversity of Macrolepiota in China and the affinities to other species of Macrolepiota are presented. In addition, the infra-generic classification of Macrolepiota is also discussed.

\section{Materials and methods}

\section{Morphological studies}

The examined materials were collected in China, and deposited in KUN (with HKAS numbers), HMAS, GDGM, BPI and HMJAU. Herbarium codes used follow Thiers (2010). Color notations indicated in the descriptions are from Kornerup and Wanscher (1978), and Color codes are according to the Online Auction Color Chart ${ }^{\mathrm{TM}}$, indicated by 'oac' before a number. The descriptions of species are in alphabetical order by species epithet. In the description, macromorphology is based on the field notes and color slides of the material; micromorphology is based on observation of the material under microscope. Melzer's reagent was used to test the amyloidy of spores. Other structures (e.g. pileal structure, cheilocystidia and basidia) were observed in 5-10 $\% \mathrm{KOH}$ and with Congo-red before making line drawings.

The abbreviation $[n / m / p]$ shall mean $n$ basidiospores measured from $m$ fruit bodies of $p$ collections in 5-10\% $\mathrm{KOH}$ solution. At least 20 basidiospores were measured for each collection. Dimensions for basidiospores are given as (a-) b-c (-d). The range b-c contains a minimum of $90 \%$ of the measured values. Extreme values (a and d) are given in parentheses. Q is used to mean "length/width ratio" of a spore in side view; avQ means average Q of all basidiospores \pm sample standard deviation.

DNA isolation and amplification

Genomic DNA was extracted from dried material. Small parts of the pileus tissue were ground in an eppendorf tube using a pestle. DNA was isolated with a modified Cetyltrimethylammonium bromide (CTAB) procedure of Doyle and Doyle (1987). ITS/5.8S rDNA were amplified using primers ITS1F and ITS4 (White et al. 1990; Gardes and Bruns 1993). PCR was performed in a total volume of $25 \mu \mathrm{l}$ containing $1 \mathrm{U}$ Taq DNA polymerase, $2.5 \mu$ l of $10 \times$ Taq polymerase reaction buffer, $1 \mu \mathrm{l}$ of $25 \mathrm{mM}$ magnesium chloride (QIAGEN Inc., Valencia, California, USA), $5 \mathrm{nmol}$ of each dNTP, $0.6 \mu \mathrm{l}$ of $10 \mu \mathrm{M}$ each of the two primers and $1 \mu \mathrm{l}$ of the DNA extract. PCR reactions were performed with 4 min initial denaturation at $95^{\circ} \mathrm{C}$, followed by 34 cycles of $50 \mathrm{~s}$ at $94^{\circ} \mathrm{C}, 40 \mathrm{~s}$ at $53^{\circ} \mathrm{C}, 50 \mathrm{~s}$ at $72^{\circ} \mathrm{C}$, and a final extension of $7 \mathrm{~min}$ at $72^{\circ} \mathrm{C}$ followed the last cycle. PCR products were purified using a QIAquick PCR purification kit (QIAGEN Inc., Valencia, California, USA). Sequencing was performed using a Bigdye terminator cycle sequencing kit (Applied Biosystems, Foster City, California, USA) following the manufacturer's protocol. Sequencing primers for the ITS regions were ITS1F and ITS4. Sequencing reactions were purified using Pellet Paint (Novagen, Madison, Wisconsin, USA) and were run on an Applied Biosystems 377 XL automated DNA sequencer. Sequence chromatograms were compiled with Sequencher 4.1 software (GeneCodes Corporation, Ann Arbor, Michigan, USA).

\section{Phylogenetic analyses}

Sequences were aligned using CLUSTAL X 1.81 followed by manual inspection and correction in MacClade (Thompson et al. 1997; Maddison and Maddison 2000). The resulting ITS data set was evaluated using two treebuilding methodologies: the maximum parsimony (MP) criterion in PAUP* and the Bayesian criterion. Gaps were treated as missing data in all analyses.

Maximum Parsimony analysis was performed using PAUP* 4.0b10 (Swofford 2004). One thousand heuristic searches were conducted with random sequence addition and tree bisection-reconnection (TBR) branch-swapping algorithms, collapsing zero-length branches and saving all minimal-length trees (MulTrees). To measure relative support for the resulting clades, 500 bootstrap replications were performed with the same parameters as for the parsimony analyses (Felsenstein 1985).

To test alternative phylogenetic relationships, the Bayesian analysis were performed using MCMC with Mr. Bayes V3.0b3 (Ronquist and Huelsenbeck 2003). Bayesian analyses were repeated 4.2 million generations and sampled every 100 . The first $25 \%$ of generations were discarded as burn-in, and Bayesian posterior probabilities (PP) were then calculated from the posterior distribution of the retained Bayesian trees. 


\section{Results}

Morphological observations

115 putative Macrolepiota specimens were examined, and 87 specimens of Macrolepiota are cited in this paper. These examined specimens represent six Macrolepiota species of which two are new to science. The six recognized species are Macrolepiota detersa, M. dolichaula, M. mastoidea, M. orientiexcoriata, M. procera and M. velosa, and they will be described in detail in the taxonomy part. Some of the previous records of $M$. dolichaula and M. procera are misidentified in the literature and these will be addressed under the material examined part of each species.

Molecular phylogenetic results

Sequences generated in this study were deposited in GenBank with accession numbers from HM125507 through HM125532, and the GenBank accession numbers for ITS sequences are given with the lists of examined collections and in the phylogenetic tree (Fig. 1). The final alignment was deposited in TreeBASE (Study Accession URL: http:// purl.org/phylo/treebase/phylows/study/TB2:S10499). The alignment comprises of 72 Macrolepiota sequences, plus 2 species of Leucoagaricus Locq. ex Singer. Leucoagaricus barssii (Zeller) Vellinga and L. meleagris (Sowerby) Singer were designated as outgroup based on a more inclusive analysis of sequences of Agaricaceae (unpublished personal data). The aligned data set included 752 base pairs, of which 22 bases were ambiguous and were excluded in the analyses. Among the analyzed 730 base pairs, 482 are constant, 48 are variable parsimony-uninformative characters, and 200 variable parsimony informative characters were used to reconstruct the phylogeny. Maximum parsimony analysis resulted in 9 equally parsimonious trees with a tree length of 448 steps, $\mathrm{CI}=0.730, \mathrm{RI}=0.947, \mathrm{HI}=0.270$. Figure 1 shows one of the most parsimonious trees. Bayesian analysis resulted in similar results, except the clade formed by Macrolepiota clelandii changed to be basal instead of the clade formed by Macrolepiota eucharis and Macrolepiota velosa. However, basal status of M. clelandii does not get statistical support.

In order to distinguish clade names from traditional taxonomic names, clade names are written in lower cases, never italicized, and preceded with the symbol " $/$ ". As shown in Fig. 1, Macrolepiota forms a well supported monophyletic group and got strong bootstrap (100\%) and bayesian PP supports (1.00). Within Macrolepiota, three clades were recovered.

Clade 1, here referred to as /volvatae clade, includes two volvate species, M. eucharis and M. velosa, this clade got $98 \%$ bootstrap support and 1.00 bayesian PP support.
Macrolepiota velosa, described from southern China, is sister to M. eucharis, a species described from Australia.

Clade 2, here referred to as /macrosporae clade, includes M. excoriata, M. mastoidea, M. orientiexcoriata, $M$. phaeodisca, M. konradii, M. psammophila, and M. subsquarrosa. This clade got $100 \%$ bootstrap and 1.00 bayesian PP support. Within this clade, collections of $M$. mastoidea from China clustered with collections from other areas; $M$. orientiexcoriata collections from China clustered together and got $64 \%$ bootstrap support.

Clade 3, here referred to as /macrolepiota clade, includes the generic type $M$. procera, and its related allies such as $M$. colombiana, M. detersa, M. dolichaula, M. fuliginosa, $M$. rhodosperma, and an undescribed species from North America. Macrolepiota clelandii, a species described from Australia which may represent an independent clade (with $100 \%$ bootstrap support), formed a sister clade of the core / macrolepiota clade (excluding M. clelandii) and got 51\% bootstrap support. For now, we tentatively include it in the / macrolepiota clade.

Within this Clade 3, the core /macrolepiota clade received $98 \%$ bootstrap support and 1.00 Bayesian posterior probabilities support. Collections of $M$. procera from China, clustered together with a Japanese collection, forming an East Asian clade. This clade got $80 \%$ bootstrap support and 0.99 Bayesian PP support and turns out to be sister to European M. procera. Collections of M. dolichaula from China and Australia form a monophyletic clade and got $100 \%$ bootstrap support and 1.00 bayesian PP support. Macrolepiota detersa, a novel species described in the present paper, clustered with 3 collections of $M$. sp. from Japan and $100 \%$ bootstrap support and 1.00 bayesian PP support.

\section{Taxonomy}

Macrolepiota detersa Z. W. Ge, Zhu. L. Yang \& Vellinga sp. nov. Fig. 2

MycoBank: MB 518349

Pileus 8-12 cm diametro, primo ovoideus vel hemisphaericus, dein convexus vel plano-convexus, albus vel albidus, squamulis crustatis, griseolis-aurantiacis vel pallide brunneis. Lamellae liberae, albae, confertae. Stipes 13.0-15.0× 1.8-2.4 cm, subcylindricus, minutus sursum, albidus, basim incrassatus. Annulus superus, albidus, membranaceus. Caro alba; sapor mitis. Basidia 30-38× 11-15 $\mu \mathrm{m}$, clavata, hyalina, 4-sporigera, raro 2-sporigera. Basidiosporae 14.0-16.0 (18.0) × (9.0) 9.5-10.5 (11.0) $\mu \mathrm{m}$, ellipsoideae, glabrae, hyalinae, dextrinoideae. Pleurocystidia absentia. Cheilocystidia clavata, lato-clavata vel pyriformia, raro subfusiformia, hyalina, 18-38×7-15 $\mu \mathrm{m}$. Squamulae pilei trichoderma, apicalis hyphis erectibus, 


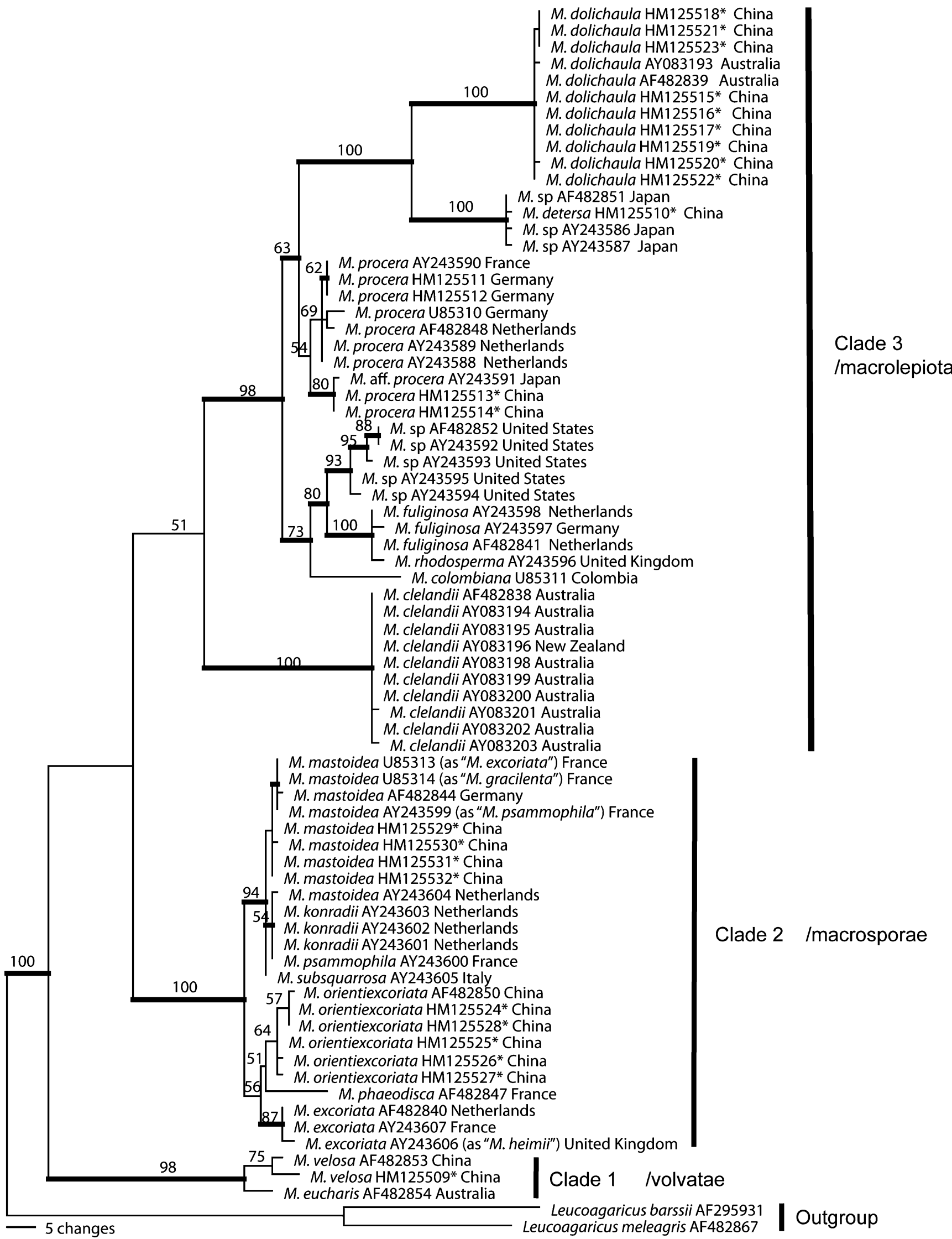


Fig. 1 One of the 9 equally parsimonious trees $(L=448, C I=0.730$, $\mathrm{RI}=0.947, \mathrm{HI}=0.270$, ) obtained in parsimony analysis of ITS sequence data. Terminal taxa represent individual specimens with GenBank accession number, and branch lengths are proportional to the number of steps (character changes) along the branch. Bootstrap support $(\geq 50 \%)$ is shown above the branches and clade with posterior probabilities greater than 0.90 is indicated with thick branches. Strict consensus tree resulted in the same topology. New sequences generated in this paper are marked with asterisks $\left(^{*}\right)$, and other sequences are mainly from Vellinga et al. (2003) and Johnson (1999)

luteis vel luteo-brunneis, subcylindricis compositae. Fibulae praesentes. Habitatio: terrestris.

Holotypus: C. L. Hou 603 (HKAS 55306), 2 Oct. 2007, Jingde County, Anhui Province, China.

Etymology: "detersa" refers to the easily detachable squamules on the pileus.

Basidiomata (Fig. 2a) medium-sized to large. Pileus 8$12 \mathrm{~cm}$ in diam., ovoid to hemispherical when young, becoming convex to plano-convex with age, white to whitish, covered with scattered, greyish orange (5B5-5B6, oac688 or oac729) to light brown (6C7-6D7, oac777) patch- or crust-like squamules which are easily detachable from the pileus; disc smooth, light brown (6C7-6D7, oac777). Lamellae free, moderately crowded, white when young, white to cream colored when mature, up to $1 \mathrm{~cm}$ in height, thin, with lamellulae, sometimes with brown spots on the lamellae. Stipe whitish, subcylindrical, 13.0-15.0 $\times$ $1.8-2.4 \mathrm{~cm}$, attenuating upwards, with tiny brownish to brown (oac721) squamules, hollow. Annulus ascending, whitish, membranous, complex, big, with brownish patchy squamules on the underside; movable when mature. Context white to whitish, spongy, unchanging when cut, odorless. Taste mild or indistinct.

Basidiospores (Fig. 2c) [48/2/1] 14.0-16.0 (18.0) $\times(9.0)$ 9.5-10.5 (11.0) $\mu \mathrm{m}, \mathrm{Q}=(1.40)$ 1.43-1.67 (1.71), avQ= $1.53 \pm 0.07$, ellipsoid to ovoid in side view, ellipsoid in front view, thick-walled, smooth, hyaline, dextrinoid, congophilous, metachromatic in cresyl blue, with a germ pore caused by an interruption in the episporium on the rounded apex, covered with a hyalinous cap in $\mathrm{KOH}$; apiculus about $1 \mu \mathrm{m}$ long. Basidia (Fig. 2d) 30-38 $\times 11-15 \mu \mathrm{m}$, clavate, thinwalled, hyaline, 4-spored, rarely 2 -spored. Cheilocystidia (Fig. 2e) $18-38 \times 7-15 \mu \mathrm{m}$, clavate to broadly clavate to pyriform, rarely subfusiform, colorless and hyaline, thinwalled. Pleurocystidia absent. Squamules on pileus (Fig. 2b) a palisade of vertically arranged subcylindric, clampless hyphae [18-40 (55) $\mu \mathrm{m}$ in length, 7-13 (15) $\mu \mathrm{m}$ in diam.], frequently septate, rarely branched, with terminal elements slightly attenuate toward the tip, with

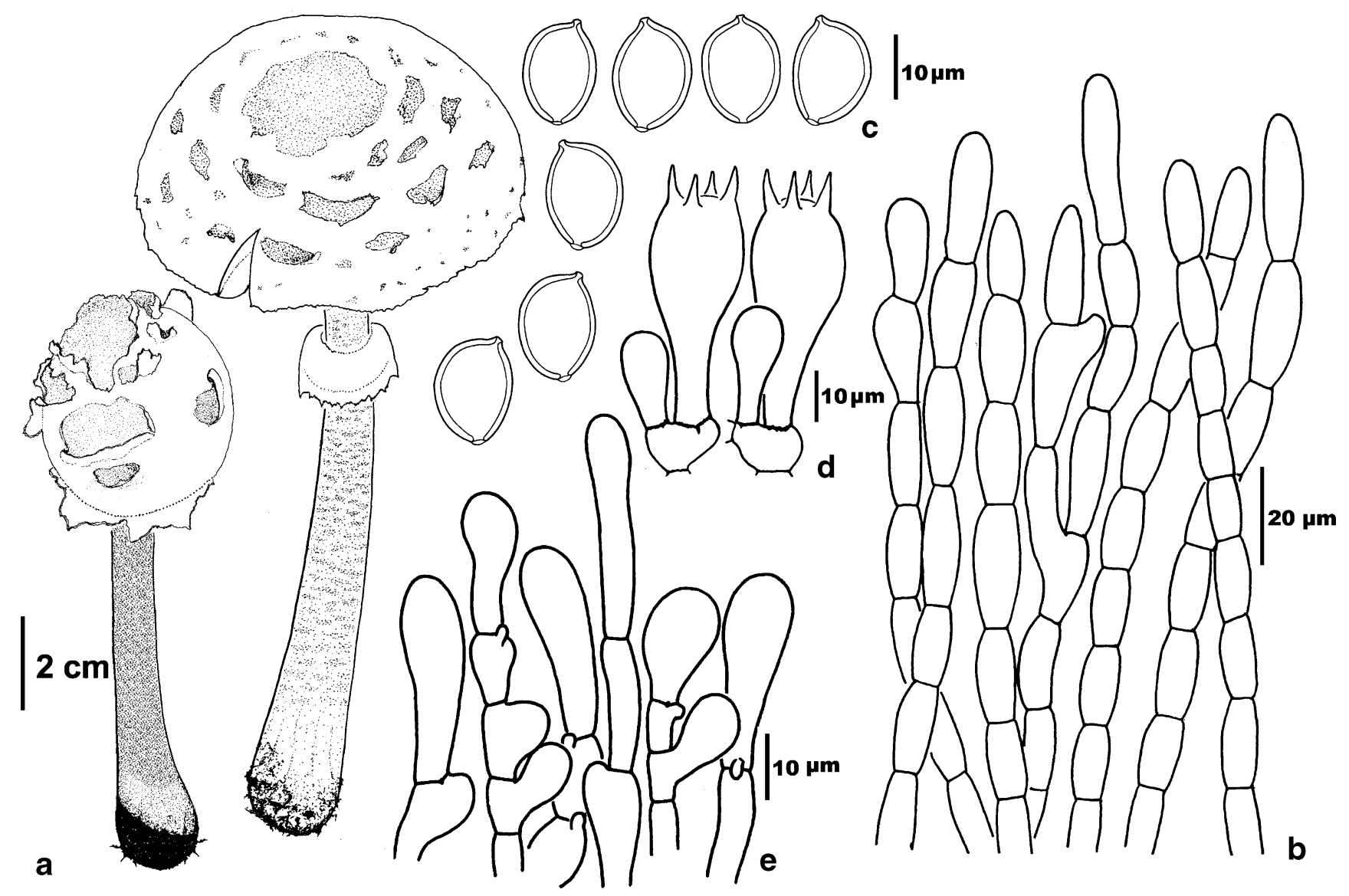

Fig. 2 Macrolepiota detersa (HKAS 55306) a. Basidiomata; b. Squamules on pileus; c. Basidiospores; d. Basidia; e. Cheilocystidia 
yellowish to brownish vacuolar pigment, slightly thickwalled. Clamp connections common at the base of basidia and cheilocystidia.

Habitat and known distribution in China: Terrestrial and saprotrophic, solitary to scattered. Distributed in eastern China.

Materials examined: Anhui Province: Jingde County, Zaoyuan, bamboo forest, 2 Oct. 2007, C. L. Hou 603 (HKAS 55306, holotype).

Comments: Macrolepiota detersa is a good edible species. It is a striking species, characterized by the combination of scattered, reflexed, patch- or crust-like, easily detachable, brown squamules on the white pileal background, a relatively big membranous annulus, and clavate to broadly clavate to pyriform cheilocystidia.

Macrolepiota detersa is very similar to $M$. procera in morphology. However, M. procera has smaller plate-like squamules on pileus which are more closely attached to the pileus, and the stipitipellis of M. procera has conspicuous contrasting dark brown squamules compared with those of $M$. detersa. Microscopically, the cheilocystidia of $M$. procera are mainly clavate to utriform, and hyphal segments in the squamules on pileus of $M$. procera are longer $(25-90 \times 7-14 \mu \mathrm{m})$ than those of M. detersa $(15-25 \times 7-$ $11 \mu \mathrm{m})$. Phylogenetically, a close relationship with $M$. dolichaula, not with $M$. procera, was suggested based on ITS sequences data set. Morphologically, $M$. detersa can easily be separated from $M$. dolichaula by forming platelike pileus squamules, and the squamules, made up of short, rarely branched filamentous hyphae. Macrolepiota detersa is also known from Japan based on DNA sequence data (Fig. 1), and probably occurs in other East Asian countries.

Macrolepiota prominens (Viv.: Fr.) M.M. Moser (in the M. mastoidea complex), originally described from Europe, comes close but differs in a protruding umbo on the pileus, a simple broad annulus, and lamellae edges which become black with age (Wasser 1993).

Macrolepiota dolichaula (Berk. \& Broome) Pegler \& Rayner in Kew Bull. 23: 365. 1969.

Agaricus dolichaulus Berk. \& Broome in Trans. Linn. Soc. London. 27: 150. 1871 ('1870').

Lepiota dolichaula (Berk. \& Broome) Sacc., Syll. Fung. 5: 32.1887.

Leucocoprinus dolichaulus (Berk. \& Broome) Pat. in Bull. trimest. Soc. mycol. Fr. 29: 215. 1913.

Leucocoprinus dolichaulus (Berk. \& Broome) Boedijn in Sydowia 5: 221. 1951.

Leucocoprinus dolichaulus var. cryptocyclus Pat. in Bull. trimest. Soc. mycol. Fr. 29: 215. 1913.

Agaricus beckleri Berk. in J. linn. Soc. 13: 156. 1872.

Lepiota beckleri (Berk.) Sacc., Syll. Fung. 5: 56. 1887. Agaricus stenophyllus Cooke \& Massee in Grevillea 15: 98. 1887.
Lepiota stenophylla (Cooke \& Massee) Sacc. in Syll. Fung. 9: 4. 1891.

Basidiomata (Fig. 3a) medium-sized to large. Pileus 6$16 \mathrm{~cm}$ in diam., fleshy, campanulate when young, become convex to plano-convex with age, with a low umbo at disc, white to whitish, covered with yellow brownish to brownish granular squamules, which become minute and sparse toward margin; disc smooth, yellow brown to brown; margin down-reflexed, appendiculate, sometimes inconspicuously short striate. Lamellae free, crowded, with short lamellulae, white when young, white to cream colored when mature, off white to cream when dried, at times hay colored after years of deposit. Stipe white to whitish, subcylindrical, $7-24 \times 0.8-2.5 \mathrm{~cm}$, attenuating upwards, with minute farinose granules; base slightly enlarged; hollow. Annulus ascending, simple, whitish, membranous. Context whitish, sometimes becoming orange at the base of the stipe when cut. Taste mild.

Basidiospores (Fig. 3c) [69/3/3] (10.0) 12.5-16.0 $\times(6.5)$ $8.0-10.5(12.0) \mu \mathrm{m}(\mathrm{x}=13.95 \pm 1.23 \times 9.26 \pm 0.99 \mu \mathrm{m}), \mathrm{Q}=$ (1.29) $1.30-1.67$ (1.94), avQ=1.51 \pm 0.13 , ovoid to ellipsoid in side view, ellipsoid in front view, thick-walled (about $0.5 \mu \mathrm{m}$ ), smooth, hyaline, dextrinoid, congophilous, metachromatic in cresyl blue, with a germ pore caused by an interruption in the episporium on the rounded apex, covered with a hyalinous cap in $\mathrm{KOH}$; apiculus $1-1.5 \mu \mathrm{m}$ long. Basidia (Fig. 3d) $28-33 \times 12-16 \mu \mathrm{m}$, clavate, thin-walled, hyaline, 4-spored; sterigmata up to $4.5 \mu \mathrm{m}$ long. Cheilocystidia (Fig. 3e) 20-33 $\times 11-15 \mu \mathrm{m}$, clavate to broadly clavate, hyaline, thin-walled. Pleurocystidia absent. Squamules on pileus (Fig. 3b) a palisade of short, frequently branched, subcylindric, clampless hyphae with terminal elements subcylindric to subfusiform, $6-15 \mu \mathrm{m}$ in diam., hyaline or with yellowish vacuolar pigment, thin-walled to slightly thick-walled. Clamp connections common at the base of basidia and cheilocystidia, but rare elsewhere.

Habitat and known distribution in China: Terrestrial and saprophytic, solitary to scattered on the ground in mixed forests or on road sides. Distributed in southern and southwestern China.

Materials examined: Fujian Province: Fuzhou City, Apr. 1934, S. Q. Deng 2473 (BPI 752291). Guangdong Province: Yangchun County, alt. 400 m, 19 May 1987, Z. S. Bi 11703 (GDGM 11703); Nan'ao County, Huanghua Mt., alt. 150-200 m, 12 Sept. 1986, Z. S. Bi and G. Y. Zheng 10789 (GDGM 10789); Boluo County, Luofu Mt., alt. 140 m, G. Li 11957 (GDGM 11957, as M. procera in Bi et al. 1994). Hainan Province: Ledong County, Jianfenglin, alt. $201 \mathrm{~m}, 4$ Aug. 1999, P. Q. Sun 4277 [HKAS 34692, as M. rhacodes (Vittad.) Singer, synonym of Chlorophyllum rachodres (Vittad.) Vellinga, in Yuan and Sun 2007]; Ledong County, Fanyangang, 11 June 1936, X. X. Liu 28414 (HMAS 24977); Ledong County, 12 


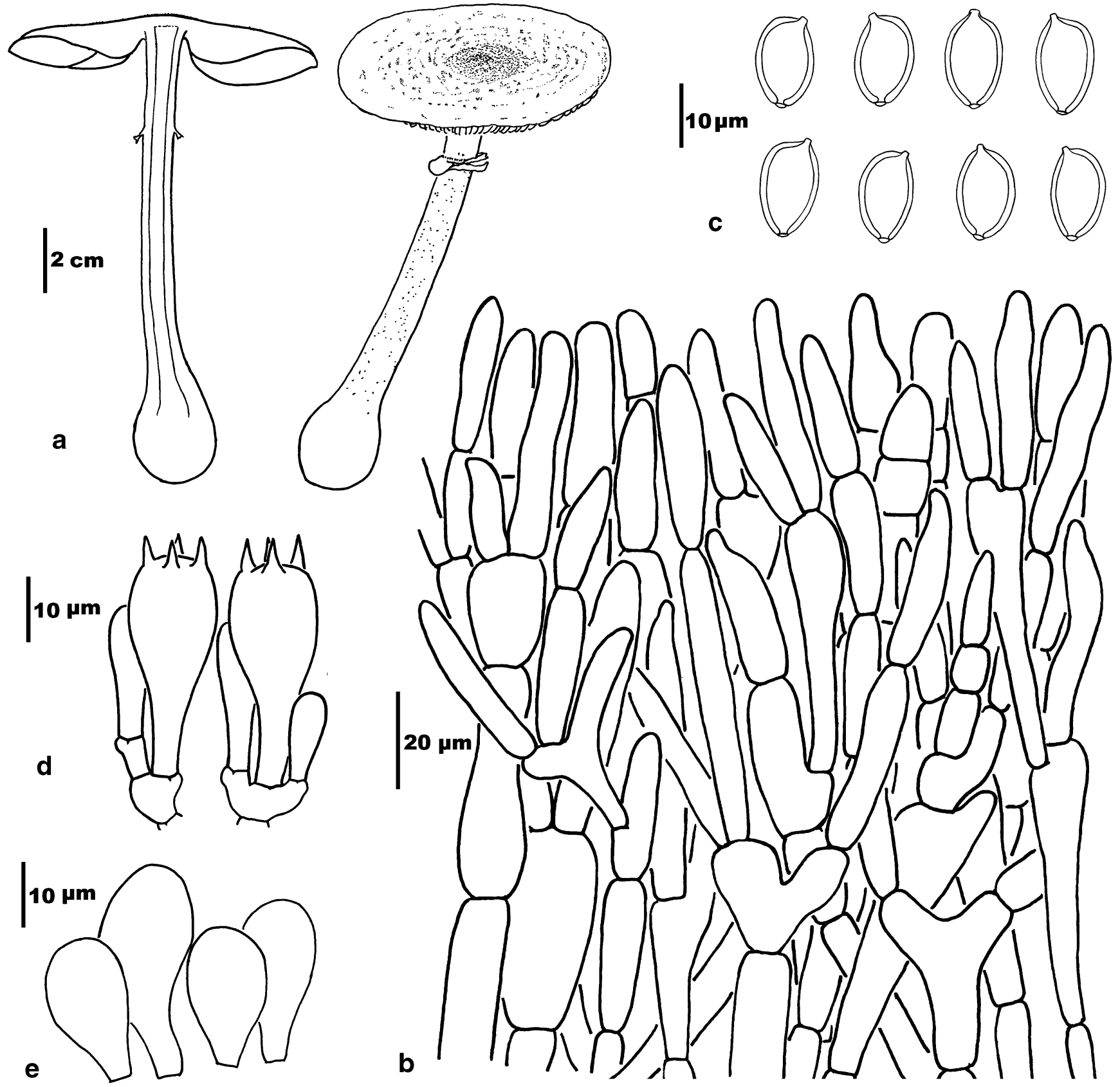

Fig. 3 Macrolepiota dolichaula (HKAS 43813, Basidiomata from HKAS 38718) a. Basidiomata; b. Squamules on pileus; c. Basidiospores; d. Basidia; e. Cheilocystidia

June1936, X. X. Liu 28415 [HMAS 22675 (M)]; Yeda Tropical Crops Research Institute, 26 May 1960, J. H. Yu and R. Liu 1402 [HMAS 29852 (M)]; Yeda Tropical Crops Research Institute, 28 May 1960, J. H. Yu and R. Liu 1461 [HMAS 29851 (M)]; Qiongzhong County, Limu Mt., 6 July 1960, J. H. Yu and R. Liu 1761 [HMAS 28817 (S)]; Lingshui County, Diaoluo Mt., 28 Oct. 1987, GDGM 14161 [as Macrolepiota procera (Scop.: Fr.) Singer in Bi et al. 1997]; Lingshui County, Diaoluo Mt., 27 Mar. 1989, GDGM 15514 (as M. procera in Bi et al. 1997). Sichuan
Province: Xichang City, 4 July1971, X. L. Mao and Q. M. Ma 129 [HMAS 36880 (S), as M. gracilenta (Krombh.) Wasser in Ying et al. 1994, as Lepiota gracilenta (Krombh.) Quél. in Ying and Zang 1994 ]; Kangding County, Gongga Mt., alt. 2800 m, under Picea and Betula, 17 July 1982, Y. Xuan (HKAS 9751); Miyi County, 27 July 1986, M. S. Yuan 1186 (HKAS 18396, as M. procera in Yuan and Sun 2007). Tibet (Xizang Autonomous Region): Mêdog (Motuo) County, alt. 850 m, 2 Aug. 1983, X. L. Mao M1160 [HMAS 52719 (S), as M. procera in Mao 1995]; 
Mêdog (Motuo), 3 Aug. 1983, X. L. Mao M1166 [HMAS 54142, as Leucoagaricus excoriatus (Schaeff.) Singer in Li et al 1995]. Yunnan Province: Dongshan, alt. 2000 m., Sept. 1982, W. K. Zheng 828 (HKAS 10342); Kunming City, 29 June 1942, W. F. Chiu [HMAS 12189 (S)]; Kunming Institute of Botany, Oct. 2000, X. H. Wang 1201 (HKAS 38171); Kunming City, Heilongtan, 15 Aug. 1974, M. Zang 954 (HKAS 954); Kunming City, Heilongtang, 18 Aug. 1975, X. J. Li 2608 (HKAS 40470); Kunming City, Heilongtan, 14 July 1976, M. Zang 2716 (HKAS 40455); Kunming City, Changchong Mt., 12 July 1984, L. S. Wang 1 (HKAS 13115); Kunming City, Heilongtan, 11 July 1986, L. S. Wang 31594 (HKAS 3365); Kunming City, Heilongtan, 20 Aug. 1987, Y. Xuan 1375 (HKAS 18311); Kunming City, Kunming Institute of Botany, 25 July 1990, Z. L. Yang 1019 (HKAS 22693); Kunming City, 20 June 1973, L. W. Xu and Y. C. Zong and Q. M. Ma 209 [HMAS 36287 (S), as Lepiota excoriata (Schaeff.) P. Kumm. in Ying et al. 1994]; Kunming City, Heilongtan, alt. 1980 m., 15 Oct. 2001, Z. L. Yang 3214 (HKAS 38718); Kunming City, Heilongtan, 17 Sept. 2001, Z. L. Yang 3203 (HKAS 38462); Fuming County, under Pinus yunnanensis, 27 July 1998, Z. J. Li and M. Zang 12977 (HKAS 34016); Songming County, Liangwang Mt., 17 Sept. 1979, G. M. Feng 1 (HKAS 4632); Songming County, Baiyi Xiang, 22 July 1998, X. H. Wang 412 (HKAS 35957); Songming County, Aziying, 29 July 1998, M. Zang 12979 (HKAS 34018); Yiliang County, 1 Sept. 1999, Z. L. Yang 2622 (HKAS 34066); Yuxi City, 20 July 1991, X. X. Liu 3a (HKAS 23404a); Gejiu City, Datun, 15 Sept. 1986, K. K. Chen 157 (HKAS 18200); Lüchun County, 11 Oct. 1973, M. Zang 325 (HKAS 325); Lufeng County, Yipinglang, alt. 1800 m, 27 June 1978, 86048 (HKAS 4493); Guangnan County, 29 June 1959, Q. Z. Wang 747 [HMAS 25146 (M)]; Qiubei County, 15 July 1959, Q. Z. Wang 787 [HMAS 25143 (M), as M. gracilenta in Ying et al. 1994]; Jinghong City, 30 Oct. 1958, S. J. Han and L. Y. Chen 5327 [HMAS 26225 (M)], Menglun County, 14 Sept. 1974, M. Zang 1522 (HKAS 1522); Menglun County, Botanical Garden, 23 Aug. 1988, Z. L. Yang 582 (HKAS 21810); 23 Aug. 1988, Z. L. Yang 582 (HKAS 21810); Menglun County, 6 Aug. 1988, Z. L. Yang 279 (HKAS 21809); Jingdong County, Ailao Mt., 18 July 2006, Z. L. Yang 4660 (HKAS 50457); Luxi County, 3 July 1977, X. J. Li 86 (HKAS 2915, as M. procera in Zang et al. 1994); Ruili City, alt. 1000 m, 25 July 1979, W. K. Zheng 79069 (HKAS 4839); Genma County, 23 Aug. 1980, M. Zang 6647 (HKAS 6647); Lijiang City, Yulong mt., alt. 2600 m., 14 Aug. 1982, J. X. Xi 333 (HKAS 10029); Lijiang City, Xiangshan, 1 Aug. 1985, M. Zang 10194 [HKAS 15093, as Macrolepiota permixta (Barla) Pacioni in Zang et al. 1996]; Lijiang City, near Jinsha river, alt. 1800 m, 6 July 2004, Z. W. Ge 61 (HKAS 45862); Malong County, 1 Aug. 1992, Y.
Xiang 3 (HKAS 25481); Pu'er (Simao) City, Caiyanghe, Heilongtan , alt. 1450 m, 16 June 2000, M. Zang 13339 (HKAS 36104); Xiaguang City, 21 Aug. 1938, C. I. Wei 8238 [HMAS 04238 (S)]; Tengchong County, Qushi, 9 Oct. 2002, H. C. Wang 247 (HKAS 42006); Longlin County, Longjiang Xiang, alt. 2100 m, 4 Sept. 2002, Z. L. Yang 3437 (HKAS 41506); Yingjiang County, 14 Aug. 1980, M. Zang 6635 (HKAS 6635); Yingjiang County, Tongbiguang Xiang, alt. $1450 \mathrm{~m}, 12$ July 2003, L. Wang 73 (HKAS 43169); Jianchuan County, Shibao Mt., alt. 2500 m, 14 Aug. 2003, Z. W. Ge 1 (HKAS 43813).

Comments: Macroscopically, M. dolichaula differs from the other species of Macrolepiota by its relatively big, umbonate pileus with minute, pallid squamules and long slender stipe which sometimes becomes orange at the base when cut. Microscopically, it differs from other species by its clavate to broadly clavate cheilocystidia, and squamules made up of a palisade of short, more branched, subcylindric, clampless hyphae.

Macrolepiota dolichaula was originally described from Sri Lanka and later also found in China (Chiu 1948), east Africa (Pegler 1977), Australia (Grgurinovic 1997), and Vietnam (Yang 2000), and northern Thailand (pers. obs.). It is considered an edible mushroom in China. Macrolepiota dolichaula is the most frequently found species in southern and southwestern China, but often misidentified as $M$. procera, M. mastoidea, M. permixta (Barla) Pacioni, or Chl. rachodes (Vittad.) Vellinga. In fact, M. procera is much browner, has a stipe with brown squamules, a pileus with plate-like squamules made up of a trichodermal layer of yellowish-brown walled hyphae which seldom branch, and larger spores; M. mastoidea usually has relatively small basidiomata, irregularly patchy or sometimes star-shaped pileal squamules, a subtle banded pattern covering of the stipe, and the rare presence of clamp connections on the base of the basidia. Macrolepiota permixta, regarded as a variety of $M$. procera by some authors, differs from $M$. dolichaula by big, plate-like squamules on the pileus, a stipe context that turns wine-red to orange-red when scratched or cut (Breitenbach and Kränzlin 1995). It might be a color variant of $M$. procera. Macrolepiota rachodes, presently placed in the genus Chlorophyllum, has plate-like pileal squamules made up of a hymeniform layer and truncated spores whose gem pore is caused by a depression in the episporium and its germ pore without a cap (Vellinga 2001; Ge and Yang 2006).

Macrolepiota mastoidea (Fr. : Fr.) Singer in Lilloa 22: 417. 1951 ('1949’).

Agaricus mastoideus Fr. : Fr., Syst. mycol. 1: 20. 1821.

Lepiota mastoidea (Fr. : Fr.) P. Kumm., Führ. Pilzk.: 135. 1871.

Lepiotophyllum mastoideum (Fr. : Fr.) Locq. in Bull. mens. Soc. linn. Lyon 11: 40. 1942. 
Leucocoprinus mastoideus (Fr. : Fr.) Locq. in Bull. mens. Soc. linn. Lyon 14: 46. 1945.

Basidiomata (Fig. 4a) medium-sized to large. Pileus 5$11 \mathrm{~cm}$ in diam., fleshy, ovoid when young, becoming convex to plano-convex when mature, with a distinct umbo at disc, white to off-white, covered with grey-brownish furfuraceous squamules, which are at first smooth and continuous, then gradually break up into irregular patches, and become minute and sparse toward margin; margin slightly appendiculate. Lamellae free, crowded, white to greyish white, with lamellulae of 2-3 lengths. Stipe subcylindrical, $6-15 \times 0.5-1.0 \mathrm{~cm}$, attenuating upwards, whitish, covered with tiny furfuraceous brownish squamules, especially above the annulus; base slightly enlarged. Annulus ascending, simple, whitish, membranous. Context whitish, not changing color when cut. Taste mild.

Basidiospores (Fig. 4c) [41/2/2] (11.0) 12.0-14.0 $(15.0) \times 8.0-9.5 \quad(10.0) \mu \mathrm{m}, \quad x=12.95 \pm 0.84 \times 8.69 \pm$ $0.60 \mu \mathrm{m}, \mathrm{Q}=(1.33) \quad 1.38-1.63$ (1.65), avQ $=1.49 \pm 0.09$, ellipsoid to ovoid in side view, ellipsoid in front view, thick-walled, smooth, hyaline, dextrinoid, congophilous, metachromatic in cresyl blue, with a germ pore caused by an interruption in the episporium on the rounded apex, covered with a hyalinous cap in $\mathrm{KOH}$; apiculus $1-1.5 \mu \mathrm{m}$

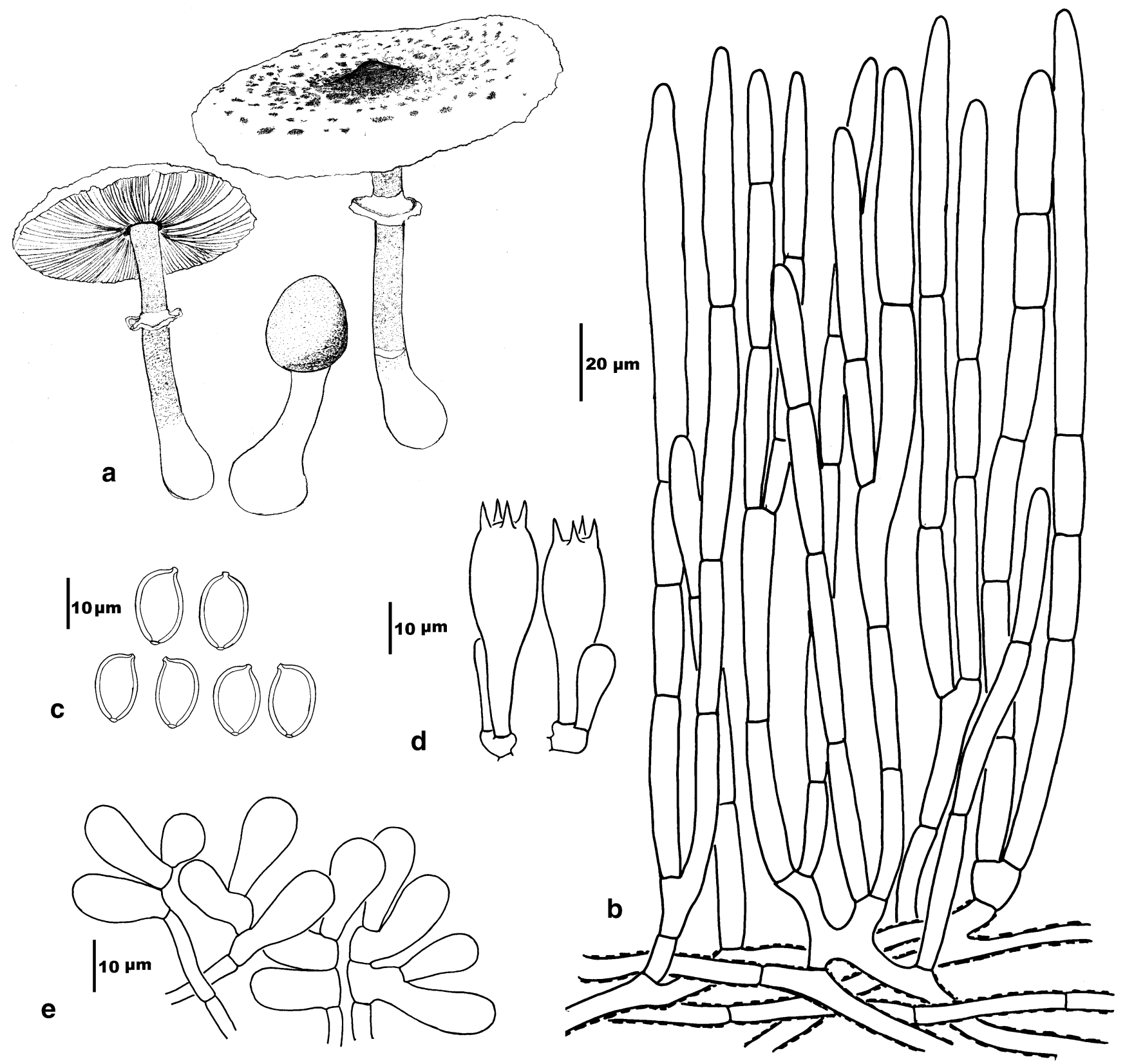

Fig. 4 Macrolepiota mastoidea (HKAS 11084) a. Basidiomata; b. Squamules on pileus; c. Basidiospores; d. Basidia; e. Cheilocystidia 
long. Basidia (Fig. 4d) $32-44 \times 12.0-14.0 \mu \mathrm{m}$, clavate, thin-walled, hyaline, 4-spored. Cheilocystidia (Fig. 4e) (10) $15-20 \times 7-10 \mu \mathrm{m}$, clavate, hyaline, thin-walled, in bunches forming a sterile edge. Pleurocystidia absent. Squamules on pileus (Fig. 4b) a palisade of subcylindric, clampless hyphae $(6-12 \mu \mathrm{m}$ in diam.), with terminal elements slightly attenuate toward the tip, with yellowish to brownish vacuolar pigment, slightly thick-walled. Clamp connections occasionally observed at the base of basidia.

Habitat and known distribution in China: Terrestrial and saprotrophic, solitary to scattered in open meadows or in mixed forests. Distributed in northeastern and southwestern China.

Materials examined: Heilongjiang Province: Yichun City, Beishan, alt. 400 m, 8 Aug. 2000, M. S. Yuan 4646 (HKAS 37384); Huma County, 29 July 2000, X.L. Mao, H. A. Wen and S.X. Sun 120 (HMAS 76557, determined as Macrolepiota crustosa L.P. Shao \& C.T. Xiang by Mao). Jilin Province: Antu County, Baima town, alt. 740 m, 17 Aug. 2004, L. F. Zhang 605 (HKAS 11084); Antu County, Jinyuetan Park, alt. 220 m, 29 Sept. 2004, L. F. Zhang 628 (HKAS 11207); Dunhua City, Huangnihe, 5 Sept. 2006, X. H. Wang 2016 (HKAS 50914). Sichuan Province: Chengdu City, 30 Sept. 2006, Z. W. Ge 938 (HKAS 51950).

Comments: Macrolepiota mastoidea is an edible species. Macroscopically, it differs from the other Chinese species of Macrolepiota by its distinctive umbonate pileus covered with grey-brownish velvet squamules which are irregularly arranged or star-shaped, and its slender stipe covered with brownish squamules. Microscopically, it is characterized by the combination of its clavate cheilocystidia, and pileal squamules made up of a palisade of rarely branched, subcylindric, clampless hyphae.

Macrolepiota mastoidea is very close to M. excoriata (Schaeff.) Wasser, but the latter has a smooth stipe and more common clamp connections on the septa of the basidia (Wasser 1993; Vellinga 2001).

Macrolepiota mastoidea is a complex of species with different morphologies, but with very small differences in ITS (Fig. 1). Now it is shown to be present in Asia as well.

Macrolepiota mastoidea was previously recorded in China, but re-examination confirmed that some collections were misidentified. e.g. HMAS 28232 was cited as $M$. mastoidea (M. gracilenta) (Ying et al. 1994), but is actually Lepiota clypeolaria (Bull.) P. Kumm.

Macrolepiota orientiexcoriata Z. W. Ge, Zhu. L. Yang \& Vellinga, sp. nov. Fig. 5

MycoBank: MB 518350

Pileus 8-12 cm diametro, convexus vel applanatus, albus vel albidus, squamulis furfuraceis, luteo-brunneis vel brunneis-aurantiacis, obtuse umbonatus. Lamellae liberae, albae, angustae. Stipes 9.0-11.0× 1.0-2.0 cm, subcylindricus, minutus sursum, albidus, basim incrassatus, non-discolorans. Annulus superus, albidus, membranaceus. Caro alba; sapor mitis. Basidia 35-52×13-16 $\mu \mathrm{m}$, clavata, hyalina, 4-sporigera, raro 2-sporigera. Basidiosporae (12.0) 13.0-15.0 (16.0)×(7.5) 8.5-10.0 (10.5) $\mu \mathrm{m}$, ellipsoideae, glabrae, hyalinae, dextrinoideae. Pleurocystidia absentia. Cheilocystidia obtusifusiformia vel subclavata, raro subcylindrica vel vesiculosa, hyalina, 20-43× 9-15 $\mu \mathrm{m}$. Squamulae pilei trichoderma, apicalis hyphus erectibus, subhyalinus vel luteo-brunneis, subcylindricis compositae. Fibulae praesentes. Habitatio: terrestris.

Holotypus: Z. W. Ge 96 (HKAS 45863), 12 July 2004, Xiangcheng County, Sichuan Province, China.

Etymology: "orienti-" refers to the locality of the type specimens collected; "excoriata" refers to the squamules of the pileus.

Basidiomata (Fig. 5a) medium to large-sized. Pileus 8$12 \mathrm{~cm}$ in diam., white to whitish, convex to plano-convex, sometimes with slightly reflexed margin, with a low umbo at disc, covered with brownish yellow (5C8, oac687) furfuraceous squamules, which become minute and sparse toward margin, revealing white flesh between them; disc smooth, brownish orange (6C7, oac719). Lamellae free, moderately crowded, white when young, white to cream colored when mature, sometimes slightly with pinkish tinge, thin, with lamellulae. Stipe whitish, subcylindrical, 9-11 $\times 1.0-2.0 \mathrm{~cm}$, gradually attenuating upwards, glabrous or with shiny hairs, hollow; base slightly enlarged to subglobose, 3.5-4.0 cm wide. Annulus ascending, whitish, membranous, slightly complex, with brownish patchy squamules on the underside. Context white to whitish, spongy, unchanging color when cut, but at edge of stipe slightly with wine red tinge, odorless. Taste mild or indistinct.

Basidiospores (Fig. 5c) [136/8/6] (12.0) 13.0-15.0 $(16.0) \times(7.5) \quad 8.5-10.0(10.5) \quad \mu \mathrm{m}, \mathrm{Q}=(1.38) \quad 1.40-1.63$ (1.67), avQ $=1.50 \pm 0.08$, ellipsoid to ovoid in side view, ellipsoid in front view, thick-walled, smooth, hyaline, dextrinoid, congophilous, metachromatic in cresyl blue, with a germ pore caused by an interruption in the episporium on the rounded apex, covered with a hyalinous cap in $\mathrm{KOH}$; apiculus not distinctive, about $1 \mu \mathrm{m}$ long. Basidia (Fig. 5d) 35-52 $\times 13-16 \mu \mathrm{m}$, clavate, thin-walled, hyaline, 4-spored rarely 2 -spored. Cheilocystidia (Fig. 5e) $20-43 \times 9.5-15 \mu \mathrm{m}$, obtusely fusiform to subclavate in most cases, occasionally subcylindric to vesiculose, hyaline, thinwalled, in bunches forming a sterile edge. Pleurocystidia absent. Squamules on pileus (Fig. 5b) a palisade of subcylindric, clampless hyphae (20-65 $\mu \mathrm{m}$ in length, 5$10 \mu \mathrm{m}$ in diam.), seldomly branched, with terminal elements slightly attenuate toward the tip, with yellowish to brownish vacuolar pigment, slightly thick-walled. 

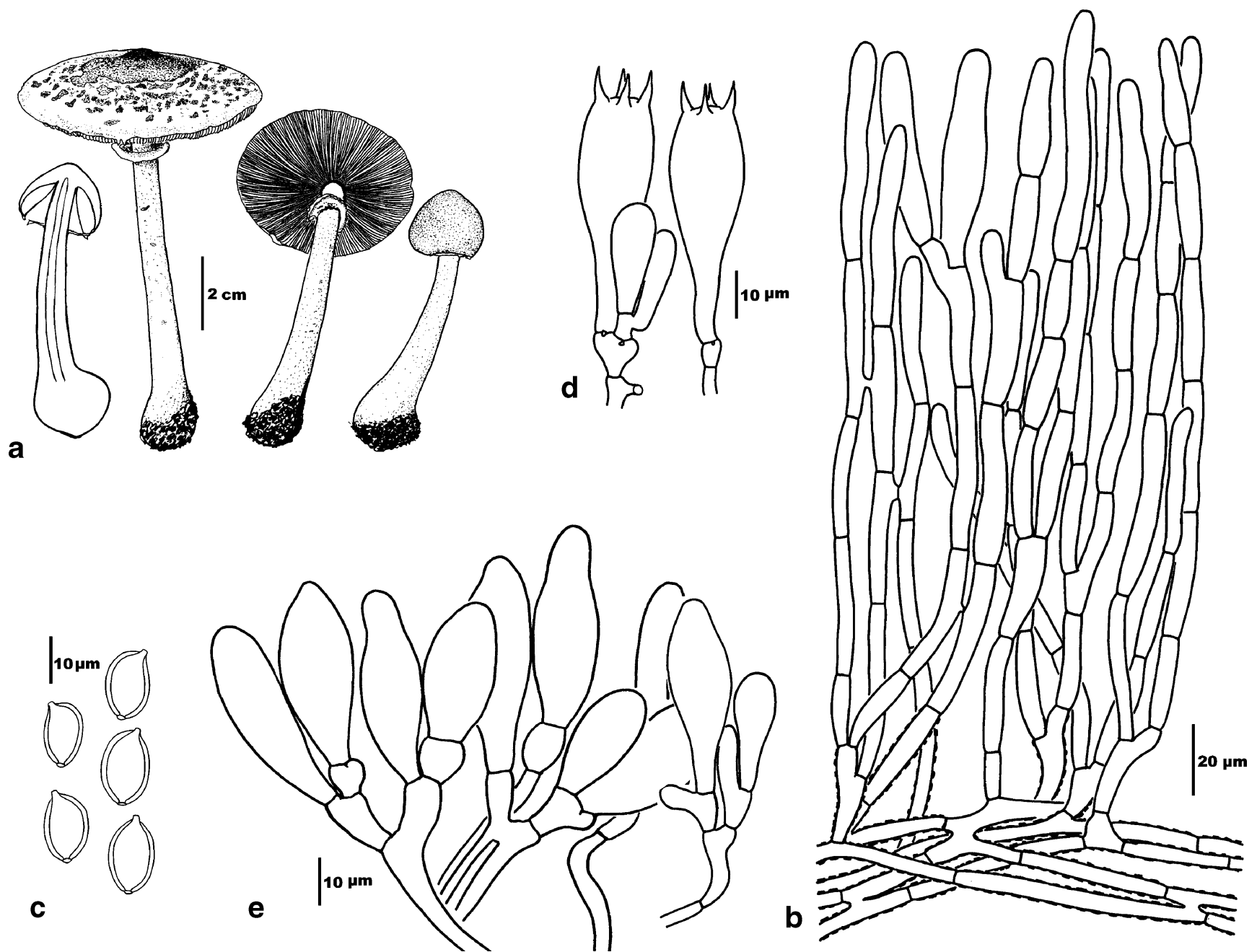

Fig. 5 Macrolepiota orientiexcoriata (HKAS45863) a. Basidiomata; b. Squamules on pileus; c. Basidiospores; d. Basidia; e. Cheilocystidia

Clamp connections common at the base of basidia and cheilocystidia.

Habitat and known distribution in China: Terrestrial and saprotrophic, solitary to scattered in open meadows or under bushes. Distributed in northern and southwestern China (Inner Mongolia and Sichuan).

Materials examined: Inner Mongolia Autonomous Region: Wulanchabu (Ulanqab) City, alt. 1590 m, 1 Aug. 1990, P. G. Liu 623 (HKAS 23040); Aug. 1994, X. L. Mao 8111 [HMAS 63157 (M); Aug. 1994, X. L. Mao 8116 [HMAS 73304 (M); Sichuan Province: Xiangcheng County, alt. 3000 m, 12 July 2004, Z. W. Ge 96 (HKAS 45863, holotype); Xiangcheng County, shagong, alt. 3000 m, 11 July 1998, Z. L. Yang 2286 (HKAS 32153); on the way from Jiulong County to Mianning County, 16 July 2005, Z. W. Ge 505 (HKAS 49001).

Comments: Macrolepiota orientiexcoriata is characterized by the combination of brownish to reddish-brown furfuraceous squamules composed of a palisade of sub- cylindric, seldomly branched, clampless hyphae, and the obtusely fusiform to subclavate cheilocystidia.

Macrolepiota orientiexcoriata is very close to $M$. excoriata (Schaeff.) Wasser both morphologically and molecularly. However, M. excoriata has a pileus with an indistinct umbo, the pileal squamules are more often starshaped, and the stipe is smooth (Candusso and Lanzoni 1990; Breitenbach and Kränzlin 1995; Vellinga 2001). Microscopically, cheilocystidia of $M$. excoriata are more often narrowly clavate to subcylindric (Wasser 1993; Vellinga 2001). The ITS data separate the two taxa, with $M$. orientiexcoriata in its own clade separate from $M$. excoriata (Fig. 1).

Macrolepiota phaeodisca Bellù, which is sister to $M$. orientiexcoriata in the phylogenetic tree, originally described from the Mediterranean region (Sardinia, Italy), grows in sandy environment, differs in the dark squamulesfibrillose pileus, and lack of clamp connections (Bellù 1984). Macrolepiota orientiexcoriata is also very similar to 
M. mastoidea. However, the latter has a distinctive umbonate pileus covered with grey-brownish velvet squamules which are irregularly arranged or star-shaped, and its slender stipe covered with pale brownish squamules.

Chlorophyllum neomastoideum (Hongo) Vellinga, originally described from Japan, is somewhat similar, but it differs from $M$. orientiexcoriata by the reddening of the flesh when cut, vesicular to clavate cheilocystidia, smaller $(7-8.5 \times 4.5-6 \mu \mathrm{m})$ and truncate spores (Hongo 1970).

Macrolepiota procera (Scop. : Fr.) Singer in Papers Mich. Acad. Sci., Arts Letters 32: 141. 1948 ('1946’).

Agaricus procerus Scop., Fl. Carn. 2: 418. 1772.

Agaricus procerus Scop. : Fr., Syst. Mycol. 1: 20. 1821.

Lepiota procera (Scop. : Fr.) S.F. Gray, Nat. Arr. Brit. Pl. 1: 601.1821.

Mastocephalus procerus (Scop. : Fr.) O. Kuntze, Rev. Gen. Pl. 2.: 1860. 1891.

Leucocoprinus procerus (Scop. : Fr.) Pat., Essai Taxon. Hymen.: 171. 1900.

Lepiotophyllum procerum (Scop. : Fr.) Locq. in Bull. mens. Soc. linn. Lyon 11: 40. 1942.

Basidiomata (Fig. 6a) medium to large-sized. Pileus 7 $25 \mathrm{~cm}$ in diam., ovoid to drum stick shaped when young, becoming convex to plano-convex with age, with an obtuse umbo at disc, white to whitish, covered with brown, dark brown to grayish brown plate-like squamules; disc smooth, brown; covering disrupting into small plate-like squamules which are irregularly arranged toward margin on the dirty white background. Lamellae free, densely crowded, thin, white when young, white to cream colored when mature, with lamellulae in 2-3 lengths. Stipe whitish, subcylindrical, $18.0-34 \times 1.0-2.2 \mathrm{~cm}$, attenuating upwards, at base enlarged $(3.5-4.0 \mathrm{~cm})$, covered with brown to dark brown velvet squamules sometimes in irregular bands, hollow or fibrous-stuffed. Annulus superior, about $5 \mathrm{~cm}$ below stipe apex, dirty white above, underside brownish, membranous, complex, moveable. Context spongy, white to cream at the pileus, grayish red to purplish brown at the stipe; not changing color. Smell not recorded. Taste mild.

Basidiospores (Fig. 6c) [64/4/4] (12.0) 13.0-16.0 $(19.0) \times 8.0-10.0(12.0) \mu \mathrm{m}, \mathrm{Q}=(1.35) \quad 1.40-1.63$ (1.65), $\mathrm{avQ}=1.50 \pm 0.07$, ellipsoid to ovoid in side view, ellipsoid in front view, thick-walled, smooth, hyaline, dextrinoid, congophilous, metachromatic in cresyl blue, with a germ pore caused by an interruption in the episporium on the rounded apex, covered with a hyalinous cap in $\mathrm{KOH}$; apiculus not distinctive. Basidia (Fig. 6d) 30-43×12$17 \mu \mathrm{m}$, clavate, thin-walled, hyaline, 4-spored. Cheilocystidia (Fig. 6e) $20-39 \times 10-23 \mu \mathrm{m}$, clavate to utriform to irregularly clavate, hyaline, thin-walled, in bunches forming a sterile edge. Pleurocystidia absent. Squamules on pileus (Fig. 6b) a palisade of subcylindric, slightly thick-walled, clampless hyphae which are 7-11 (14) $\mu \mathrm{m}$ in diam., seldom branched, with terminal elements slightly attenuate toward the tip, with yellowish brown vacuolar pigment, slightly thick-walled. Clamp connections common at the base of basidia and cheilocystidia.

Habitat and known distribution in China: Terrestrial and saprotrophic; solitary to scattered on edge of the forest or in the forest dominated by coniferous and Fagaceous trees. Distributed in northeastern and eastern China (Heilongjiang, Jilin, Shangdong, Jiangsu and Guangdong).

Specimens examined: Guangdong Province: Changjiang County, Bawangling, GDGM 11851; Heilongjiang Province: Hulin City, Dongfanghong natural reserve, 19 Sept. 2004, Tolgor 2702 (HMJAU 2702). Jilin Province: Fusong County, Songjianghe, alt. 1300 m, 12 Aug. 2000, M. S. Yuan 4659 (HKAS 37383); Yanbian Chosenzu Zizhizhou, Baihe, alt. 840 m, 15 Aug. 2004, L. F. Zhang 517 (HKAS 8108); Fusong County, Lushuihe, alt. 625 m, 11 Aug. 2004, L. F. Zhang 381 (HKAS 5722). Shangdong Province: 26 Aug. 1980, H. A. Wen and Y. C. Zong 10 [HMAS 42757 (M)]. Jiangsu Province: Nanjing City, 21 June 1931, S. Q. Teng 490 (BPI 75231).

Comments: Macrolepiota procera is an edible species. Morphologically, it is characterized by the big, fleshy basidiomata, the stipe covered with zig-zag banded squamulae, and the squamules on pileus composed of a palisade of subcylindric, slightly thich-walled, clampless brown hyphae.

Macrolepiota fuliginosa (Barla) M. Bon and M. permixta (Barla) Pacioni are two closely related species. But $M$. fuliginosa has grayish brown basidiomata, and M. permixta red-brown basidiomata (Bon 1996; Candusso and Lanzoni 1990; Vellinga 2001).

According to the ITS tree, the East Asian collections differ from those of Europe; this may indicate that collections from East Asia and those from Europe represent different phylogenetic species. As we have not found discernable morphological characters to separate them, we continue to recognize the East Asian collections as $M$. procera.

Macrolepiota velosa Vellinga \& Zhu L. Yang in Mycotaxon 85: 184. 2003.

Basidiomata (Fig. 7a) medium to large-sized. Pileus 7$9 \mathrm{~cm}$ in diam., plano-convex, with a wide indistinct umbo, purplish to pale brownish or grey with purplish tinge, fibrillose, covered with brown to dark brown furfuraceous squamules; disc smooth, dark brown. Sometimes with white to dirty white membranous volval remnants as patches on the surface. Lamellae free, remote from the stipe, moderately crowded, white to cream colored, with whitish cystidiose edge. Stipe brownish to purplish brown, cylindrical, $10-17 \times 0.4-1.0 \mathrm{~cm}$, attenuating and paler upwards, with fine fibrils or squamules, hollow; base slightly enlarged up to $1.3 \mathrm{~cm}$. Annulus ascending, whitish 


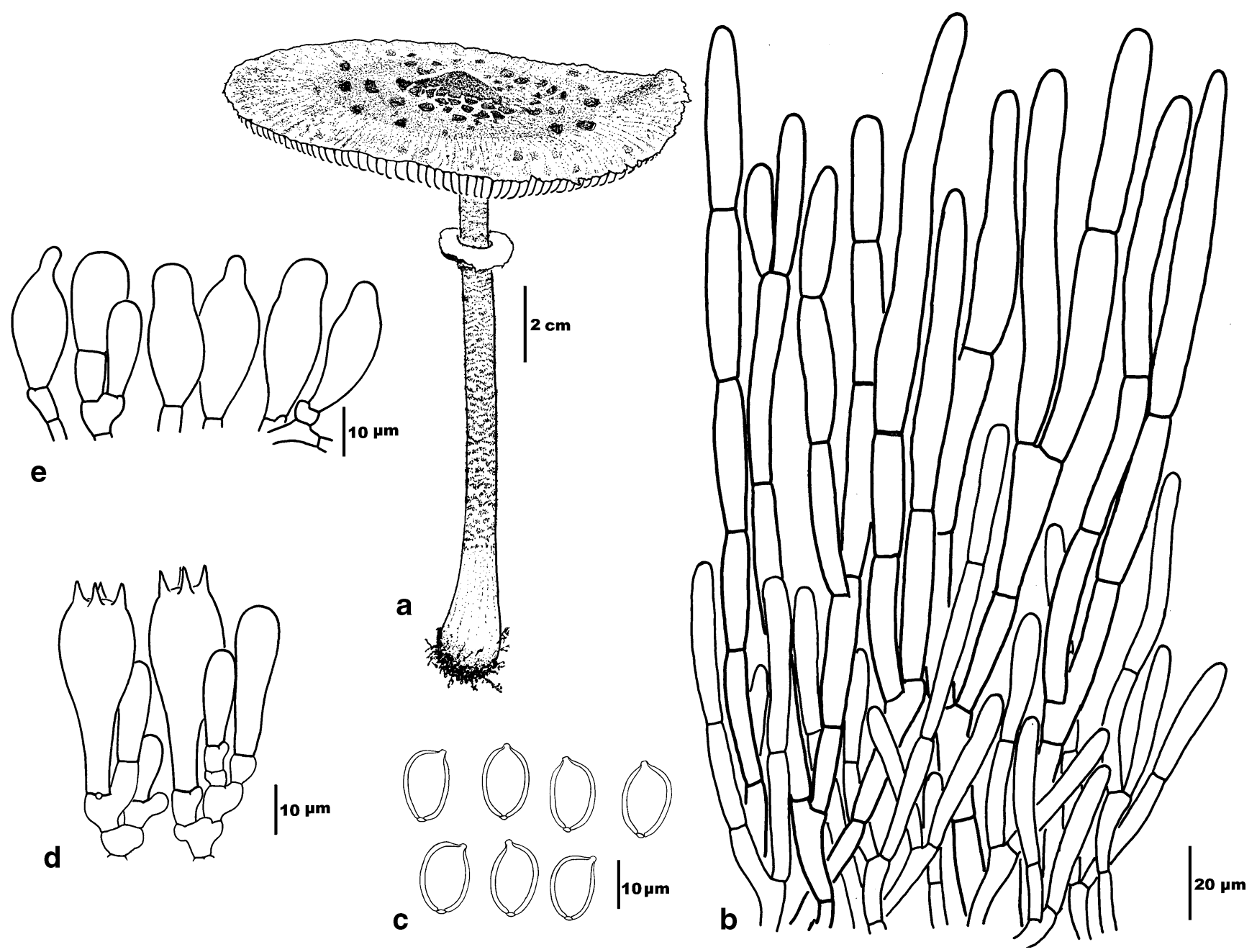

Fig. 6 Macrolepiota procera (HKAS 8108) a. Basidiomata; b. Squamules on pileus; c. Basidiospores; d. Basidia; e. Cheilocystidia

on upperside with brown rim, and brownish underside, membranous. Volva limbate, white, membranous. Context white, with pinkish to brownish tinge both in pileus and stipe, odorless. Smell indistinct. Taste mild or indistinct.

Basidiospores (Fig. 7c) [145/6/6] (8.0) 9.0-11.0 (11.5) $\times$ (5.5) $6.0-7.5(8.0) \mu \mathrm{m}, \mathrm{Q}=(1.2) 1.36-1.5$ (1.62), avQ= $1.42 \pm 0.06$, amygdaloid-ellipsoid in side view, ellipsoid in front view, thick-walled, smooth, hyaline, dextrinoid, congophilous, metachromatic in cresyl blue, with a germ pore caused by an interruption in the episporium on the rounded apex, covered with a hyalinous cap in $\mathrm{KOH}$, apiculus not distinctive, about $1 \mu \mathrm{m}$ long. Basidia (Fig. 7d) 25-30 $\times 9.5-11.5 \mu \mathrm{m}$, clavate, 4-spored, without clamp connections. Cheilocystidia (Fig. 7e) 44-68×4.5-7.5 $\mathrm{m}$, cylindrical, some slightly widened at apex, with rounded apex, with grayish granular contents, and refractive patch at apex, thin-walled, forming a sterile edge. Pleurocystidia absent. Squamules on pileus (Fig. 7b) a palisade of ellipsoid to subglobose, clampless elements $(20-65 \mu \mathrm{m}$ in length, $5-10 \mu \mathrm{m}$ in diam.) in chains, rarely branched, with clavate to narrowly clavate terminal elements (up to $100 \times$ $25 \mu \mathrm{m}$ ), slightly thick-walled, brownish, interspersed with some cylindrical hyphae 5-10 $\mu \mathrm{m}$ wide. Velar patches made up of hyaline, non-colored, cylindrical narrow hyphae about 2-4 $\mu \mathrm{m}$. Clamp connections not observed at the base of basidia, cheilocystidia.

Habitat and known distribution in China: Terrestrial and saprotrophic, solitary to scattered on the ground in mixed forest. So far only found in Yunnan and Hainan.

Materials examined: Yunnan Province: Jinghong City, Damenglong, alt. 650 m, 14 Aug. 1995, Z. L. Yang 2172 (HKAS 29487); Mengla County, Menglun Natural Reserve, alt. 700-800 m, 2 Sept. 1990, Z. L. Yang 1271 (HKAS 23312); Mengla County, Menglun Nature Reserve, alt. 580 m, 12 Aug. 1988, Z. L. Yang 381 (HKAS 21808); Mengla County, Menglun, Botanical Garden, alt. 580 m, 12 Oct. 1989, Z. L. Yang 767 (HKAS 22131). Hainan Province: Changjiang County, Bawangling Nature Re- 


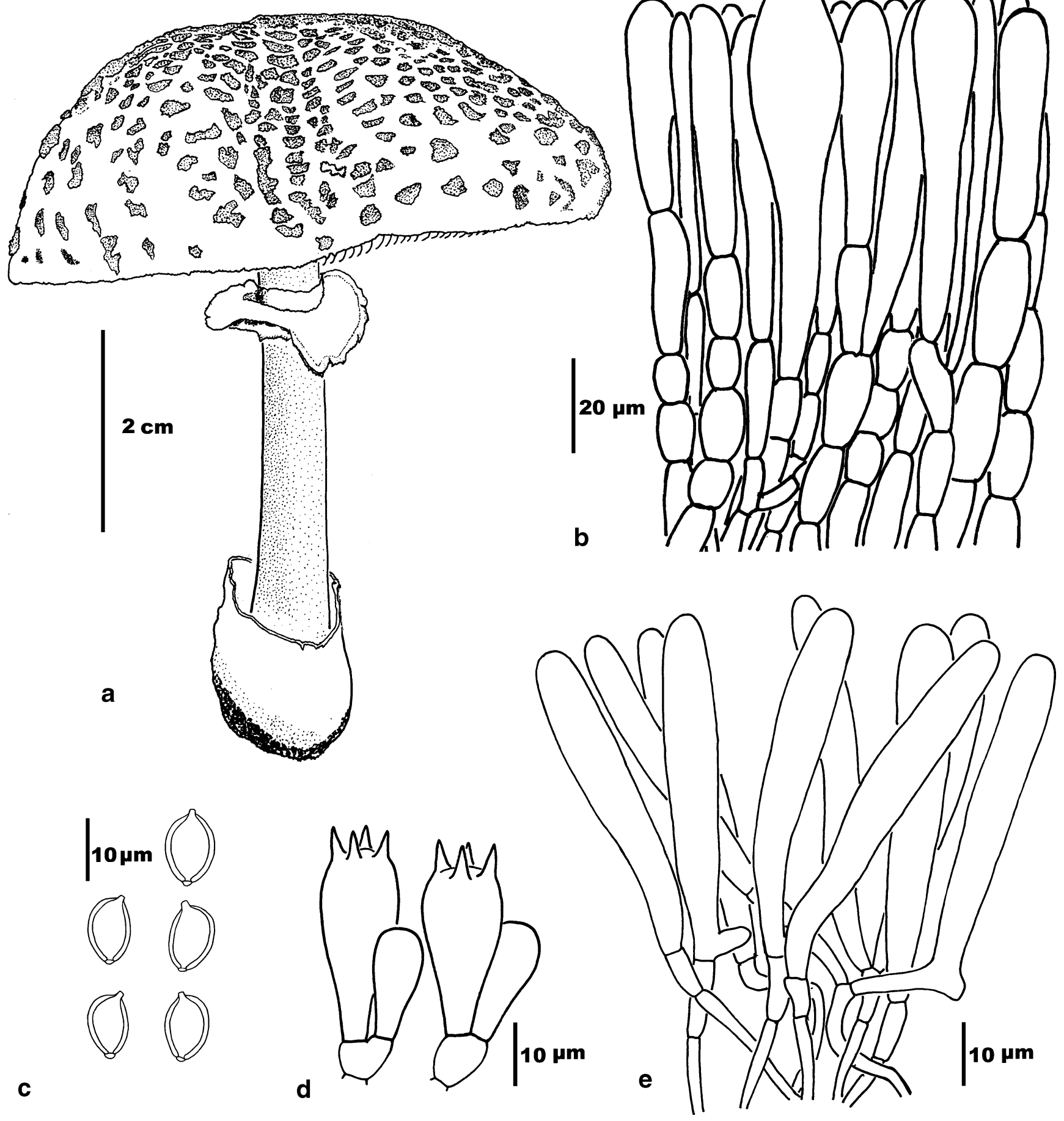

Fig. 7 Macrolepiota velosa (HKAS 29487, Basidioma from HKAS 58051) a. Basidiomata; b. Squamules on pileus; c. Basidiospores; d. Basidia; e. Cheilocystidia

serve, alt. 680 m, 19 Aug. 2009, N. K. Zeng 518 (HKAS 58050); same locality, alt. 693 m, 23 Aug. 2009, N. K. Zeng 562 (HKAS 58051).

Comments: The distinctive characters of M. velosa are the basidiomata with a volva at the base of the stipe, sometimes with white to whitish volval remnant patches on the pileus; small basidiospores and the squamules made up of ellipsoid to subglobose brown-walled elements in chains interspersed with some brown filamentous hyphae.

Comparing to other Macrolepiota species with a volva, M. pulchella de Meijer \& Vellinga from Brazil differs from $M$. velosa by longer basidiospores $(10.0-14.5 \times 6.0$ 
$7.5 \mu \mathrm{m})$, shorter cheilocystidia $(23-42 \mu \mathrm{m})$, and the squamules made up of clavate elements and long, colorless emerging hyphae; M. eucharis Vellinga \& Halling from Australia differs in larger basidiospores $(10.8-15.5 \times 7.0$ $9.0 \mu \mathrm{m})$, wider and shorter cheilocystidia $(25-53 \times 5.0$ $12.0 \mu \mathrm{m}$ ), and squamules lacking ellipsoid to globose or clavate elements. Macrolepiota brunnescens Vellinga, also from South America, has velar patches on the pileus, but becomes brown in all part. Macrolepiota clelandii Grgur. superficially resembles $M$. velosa, but differs from the latter by the absence of a volva at the base of the stipe, the predominantly 2 -spored basidia, and much bigger spores up to $28.5 \times 15.5 \mu \mathrm{m}$ (Vellinga 2003).

Macrolepiota velosa is also known from northern Thailand; its edibility remains unknown.

Doubtful species and taxa recorded from China but with uncertainty

Macrolepiota crustosa L.P. Shao \& C.T. Xiang in Journal of North-eastern Forestry Institute 8 (4): 36. 1980.

The original description reads:

"Fructificatio solitarius vel gregarius; pileus 6-13, cm. latus, carnosus, mollis e globoso demum explanatus vel depressus, centro mamillis, crustis albo-cinerus vestitus, centro demum fuligineus, lobo frastoso, peripheria facile exutus, exer albo-caro, polygonalibus, fibrillosis; caro alba, fracta demum lutescens, inodora, sapore grato; stipes cavus, levis, albo-griseus, bulbo amplisssimo, 17-22 cm. longus, 8$11 \mathrm{~mm}$. crassus; annulus mobolis, fibroso-lacerus; lamellae distantes, latae albae, fractae incarnatae; sporae ovoideoellipsoideae, chlorino-hyalinae, $11-14.5 \times 6-8 \mu$; basidia cylindraceo-clavata, 34-44×10-11.9 $\mu$.-Esculenta.

Hab: Heilongjiang, Dai-ling, ad terram in pinelis, 18, VIII, 1974, Shao Li-ping, Siang Cun-ti, no. 74210 (Typus)

Obs: Species Macrolepiotae procerae et Macrolepiotae rachodese affinis, a priore stipes minute squamis differt, a posteriore carne aere rubescente et in centro pileo emamillae, sapore parum grato facile dignoscendo differ."

Comment: According to the description and the habit depicted in Fig. 2 in Shao et Siang (1980), M. crustosa is more similar to $M$. mastoidea than to $M$. procera, but "the smooth stipe and the white context changes yellow" reminds us of a Chlorophyllum species. HMAS 76557, collected from Huma in Heilongjiang province and determained by X. L. Mao as M. crustosa, turned out to be a misidentification of $M$. mastoidea. Because the type of M. crustosa is lost, its taxonomic uncertainty remains.

Macrolepiota prominens (Viv. : Fr.) M.M. Moser, in Gams, Kleine Kryptogamenflora, Edn 3 (Stuttgart) 2b/2: 184. 1967

Macrolepiota prominens, clearly belongs to the $M$. mastoidea group, is characterized by a conspicuous protruding umbo on the pileus, a simple broad annulus, and lamellae edges which become black with age (Wasser 1993). Teng (1996) and Mao (2000) recorded this species for China. As there is no specimens cited, and no specimens examined fit with characters mentioned above, voucher specimens for this species still need to be found or collected.

Key to the recognized species of Macrolepiota from China

1 Basidiomata with a volva at the base of the stipe M. velosa

1* Basidiomata without a volva at the base of the stipe

2 Pileus surface with brown plate-like squamules; annulus complex; clamp connections common at the base of the basidia

3 Stipe surface with conspicuous fine brown squamules on whitish background; pileus squamules made up of yellowish-brown walled long hyphal segments, mainly 25-90×7-11 (14) $\mu \mathrm{m}$

M. procera

3* Stipe surface with fine brown squamules on whitish background; pileus squamules made up of yellowish-brown walled short hyphal segments, mainly $15-25 \times 7-11 \mu \mathrm{m}$

M. detersa

2* Pileus surface with pale ochraceous to brown fine squamules; annulus simple, or only slightly thicker near the edge; clamp connections absent or present

4 Stipe surface with brown squamules; usually without clamps at the base of basidia

4* Stipe surface smooth; usually with clamps at the base of basidia

M. mastoidea 
5 Stipe base sometimes becomes orange when cut, pileus squamules composed of more frequently branched hyphae, cheilocystidia mainly clavate to broadly clavate

M. dolichaula

5* Stipe base not changing color when cut, pileus squamules composed of seldom branched hyphae, cheilocystidia mainly obtusely fusiform to clavate

M. orientiexcoriata

\section{Discussion}

New species within Macrolepiota and species diversity in China

As shown in Fig. 1, M. detersa is phylogenetically closely related to, but distinct from $M$. dolichaula and M. procera based on the ITS data. Similarly, M. orientiexcoriata is phylogenetically closely related to $M$. excoriata, $M$. mastoidea, and M. phaeodisca, but forms a clade of its own. As both $M$. detersa and M. orientiexcoriata have discrete characters to tell them apart from the currently described species, we described them as new species in this paper.

In addition, the result that $M$. detersa clustered with 3 collections of $M$. sp. from Japan, which as a whole gets strong statistical supports, $100 \%$ of bootstrap and 1.00 bayesian PP support respectively, indicates that the three Japanese collections are $M$. detersa (Fig. 1).

By far, Europe is the species richest region of Macrolepiota, with 11 species in the current sense recorded (Candusso and Lanzoni 1990; Vellinga 2001; but numbers depend on species concepts), then followed by Asia with 9 species recorded (Manjula 1983; Pegler 1986; Shao and Xiang 1981; Teng 1996; Vellinga and Yang 2003), and 4 species in east Africa (Pegler 1977), and 3 species in Australia (Grgurinovic 1997; Vellinga 2003). Based on our present results, at least 6 morphological species were found in China, with representatives belonging to three different phylogenetic clades recovered by the analyses of the ITS data set.

Morphological features of the major monophyletic clades within Macrolepiota

The monophyly of Macrolepiota shown here is in accordance with earlier findings based on ITS (Vellinga et al. 2003). Vellinga et al. (2003) detected similar major clades (Fig. 1 in their paper), however, only one of the clades containing M. excoriata, M. mastoidea, M. "spec. nov. 1" (which is $M$. orientiexcoriata) and M. phaeodisca got bootstrap support. In our present study, two of the three clades recovered by the ITS data set got strong bootstrap and Bayesian post probability supports. The separation of the three clades is supported by morphological characters and will be discussed as following:

/volvatae clade (Clade 1) is characterized by species having a volva at the base of the stipe, finely squamulous stipe surfaces, relatively small (usually less than $15 \mu \mathrm{m}$ ) amygdaliform-ellipsoid spores, and no clamp connections at the base of the cheilocystidia and basidia. Species of this clade so far are mainly distributed in tropical regions (Vellinga 2003; Vellinga and Yang 2003).

/macrosporae clade (Clade 2) is characterized by a smooth stipe, a simple annulus and rare clamp connections. In contrast to those in /macrolepiota clade, species within this clade do not have big platelike squamules on pileus, but furfuraceous fine squamules composed of a single layer with rarely branched, pale brownish and thin-walled cylindrical hyphae.

/macrolepiota clade (Clade 3) is characterized by having a complex annulus, relatively big (usually 14$20 \mu \mathrm{m}$ ) ovoid-ellipsoid spores, with a common presence of clamp connections at the base of the cheilocystidia and basidia, stipe usually 2-3 time the pileus diameter (Bon 1996), and the cheilocystidia are mainly broadly clavate. The stipes usually have fine brown squamules, but $M$. dolichaula and $M$. clelandii have farinose stipe surfaces. The pileus covering of species within this clade forms big-plate like squamules, and the squamules are composed of two layers with the terminal layer composed of seldom branched brownish and thick-walled cylindrical hyphae arising from a layer which is composed of thin-walled, often branched hyphae (but $M$. dolichaula is the exception here as well).

Infrageneric classification and systematic position of species with volva in Macrolepiota

In traditional taxonomic classifications, Singer partitioned Macrolepiota into two groups (section Macrolepiota and section Macrosporae) based on the presence or absence of clamp connections (Singer 1986). Bon (1996) divided the genus Macrolepiota into three sections by adding sect. Laevistipedes (Pázmány) Bon. Vellinga (2003) transferred 
the section Laevistipedes to the genus Chlorophyllum, and Vellinga and Yang (2003) synonymized Volvolepiota with Macrolepiota without discussion of the taxonomic positions of those species with a volva within the genus. In this study, our molecular phylogenetic analysis recovered three major clades with strong statistical support. This result and the corresponding morphological characters of each clade indicate that Macrolepiota could be divided into three sections. /macrolepiota clade and /macrosporae clade mainly correspond to the current infra-generic classification proposed by Bon (1996). Considering the species with a volva form a well-supported /volvatae clade (Clade 1), we propose a new section to accommodate the species with a volva within Macrolepiota.

Macrolepiota sect. Volvatae Z. W. Ge, Zhu L. Yang \& Vellinga, sect. nov.

MycoBank: MB 518351

Stipes basi marginatus-bulbosus, volvatus, Basidiospora parvula, 15.5 um minus. Fibulae absentes.

Stipe with a volva at the base, annulus simple or only thickening at the edge of the annulus or only somewhat reflexed near the annulus margin, basidiospores less than $15.5 \mu \mathrm{m}$ in length, clamp connections absent.

Type species: Macrolepiota velosa Vellinga \& Zhu. L. Yang in Mycotaxon 85: 184 (2003).

Other species included in this section are Macrolepiota pulchella de Meijer \& Vellinga, M. eucharis Vellinga \& Halling and M. brunnescens Vellinga.

Acknowledgements Z. W. Ge would like to thank Dr. D. S. Hibbett (Clark University, USA) for allowing him to generate some sequences in his lab, and Prof. D. H. Pfister for support during his stay in the Harvard University Herbaria. The authors are very grateful to Dr. C. L. Hou for sending the type material and image of Macrolepiota detersa. Thanks are also due to Dr. T.H. Li, Guangdong Institute of Microbiology (GDGM), and Dr. Y. J. Yao, Institute of Microbiology, Chinese Academy of Sciences (HMAS) for allowing us access to the relevant specimens in their herbaria. This study was supported by the National Natural Science Foundation of China (grants No. 30800004), the Natural Science Foundation of Yunnan Province (No. 2008CD164), the Ministry of Science and Technology of China (2008FY110300), the Joint Funds of the National Natural Science Foundation of China and Yunnan Provincial Government (No. U0836604) the Hundred Talents Program of the Chinese Academy of Sciences, and the National Key Technology R \& D Program (No. 2008BADA1B00).

Open Access This article is distributed under the terms of the Creative Commons Attribution Noncommercial License which permits any noncommercial use, distribution, and reproduction in any medium, provided the original author(s) and source are credited.

\section{References}

Bellù F (1984) Contributo al genere Macrolepiota Singer-2. Bollettino Gruppo Micologico G. Bresadola 27(1-2):5-20
Bi ZS, Zheng GY, Li TH (1994) Macrofungus Flora of Guangdong Province. Guangdong Science and Technology, Guangdong, p 879, in Chinese

Bi ZS, Li TH, Zhang WM, Song B (1997) A preliminary agaric flora of Hainan Province. Guangdong Higher Education, Guangzhou, p 388, in Chinese

Bon M (1996) Die Großpilzflora von Europa 3. Lepiotaceae (übersetzt und bearbeitet von F. Medjebeur-Thrun F., Thrun WU). Eching: IHW-Verlag

Breitenbach J, Kränzlin F (1995) Fungi of Switzerland, Vol. 4. Agarics 2nd part. Verlag Mykologia, Lucerne (Switzerland)

Candusso M, Lanzoni G (1990) Fungi Europaei 4. Lepiota s. 1. Saronno, Giovanna Biella

Chiu WF (1948) The Amanitaceae of Yunnan. Sci. Rept. Natl. Tsing Hua Univ. Ser. B., Biol. and Psychol. Sci 3(3):165-178

Ding ZQ, Huang SZ (2003) Characteristics and high-yield culture technique of Macrolepiota procea. Edible Fungi 4:33, in Chinese

Doyle JJ, Doyle JL (1987) A rapid DNA isolation procedure for small quantities of fresh leaf material. Phytochem Bull 19:11-15

Felsenstein J (1985) Confidence limits on phylogenies: an approach using the bootstrap. Evolution 39:783-791

Gardes M, Bruns TD (1993) ITS primers with enhanced specificity for basidiomycetes - application to the identification of mycorrhizae and rusts. Mol Ecol 2:113-118

Ge ZW, Yang ZL (2006) The genus Chlorophyllum (Basidiomycetes) in China. Mycotaxon 96:181-191

Grgurinovic CA (1997) Larger fungi of South Australia. Botanic Gardens of Adelaide and State Herbarium and Flora and Fauna of South Australia Handbooks Committee, Adelaide

Hongo T (1970) Notulae mycologicae 9. Memoirs of the Shiga University. Nat Sci 20:49-54

Johnson J (1999) Phylogenetic relationships within Lepiota sensu lato based on morphological and molecular data. Mycologia 91:443-458

Kirk PM, Cannon PF, Minter DW, Stalpers JA (2008) Dictionary of the fungi, 10th edn. CABI, Wallingford

Kornerup A, Wanscher JH (1978) Methuen handbook of color, 3rd edn. Eyre Methuen Ltd., London

Maddison DR, Maddison WP (2000) MacClade 4: analysis of phylogeny and character evolution. Sinauer Associates, Sunderland

Manjula B (1983) A revised list of the agaricoid and boletoid basidiomycetes from India and Nepal. Proc Indian Acad Sci (Plant Sciences) 92(2):81-213

Mao XL (1995) Macrofungal flora of the Mt. Namjagbarwa Region. In: Li BS, Mao XL, Wang ZW (eds) Biota of the Mt. Namjagbarwa Region. Science, Beijing, p 118, in Chinese

Mao XL (2000) The macrofungi in China. Henan Science and Technology, Zhengzhou, p 719, in Chinese

Mao XL (2009) The macromycetes of China. Science, Beijing, p 816, in Chinese

Pegler DN (1977) A preliminary Agaric Flora of East Africa. Kew Bulletin Additional Series 6: 1-615. London, HMSO

Pegler DN (1986) Agaric Flora of Sri Lanka. Kew Bulletin Additional Series 12:1-519

Ronquist F, Huelsenbeck JP (2003) MrBayes 3: Bayesian phylogenetic inference under mixed models. Bioinformatics 19:1572-1574

Shao LP, Xiang CT (1981) ('1980') The study on the Macrolepiota spp. in China. Journal of Northeastern Forestry Institute 4:35-38

Singer R (1948) ('1946') New and interesting Species of Basidiomycetes. Papers Michigan Academy of Science, Arts and Letters 32:103-150

Singer R (1959) Dos generos de hongos nuevos para Argentina. Bol Soc Argent Bot 8:9-13

Singer R (1986) The Agaricales in modern taxonomy, 4th edn. Koeltz Scientific Books, Koenigstein

Swofford DL (2004) PAUP*. Phylogenetic analysis using parsimony (* and other methods), Version 4.01. Sinauer, Sunderland, Massachusetts 
Teng SC (1996) In: Korf RP (ed) Fungi of China, Mycotaxon Ltd, Ithaca, New York, pp 453-456

Thiers B (2010) [continuously updated]. Index Herbariorum: A global directory of public herbaria and associated staff. New York Botanical Garden's Virtual Herbarium. http://sweetgum.nybg.org/ $\mathrm{ih} /]$

Thompson JD, Gibson TJ, Plewniak F, Jeanmougin F, Higgins DG (1997) The CLUSTAL_X windows interface: flexible strategies for multiple sequence alignment aided by quality analysis tools. Nucleic Acids Res 25:4876-4882

Vellinga EC (2001) Macrolepiota. In: Noordeloos ME, Kuyper TW, Vellinga EC (eds) Flora Agaricina Neerlandica, vol. 5. A. A. Balkema Publishers, Lisse (Netherlands)

Vellinga EC (2003) Chlorophyllum and Macrolepiota (Agaricaceae) in Australia. Austr Syst Bot 16:361-370

Vellinga EC, Yang ZL (2003) Volvolepiota and Macrolepiota-Macrolepiota velosa, a new species from China. Mycotaxon 85:183-186

Vellinga EC, De Kok RPJ, Bruns TD (2003) Phylogeny and taxonomy of Macrolepiota (Agaricaceae). Mycologia 95(3):442-456
Wasser SP (1993) Tribes Cystodermateae Sing. and Leucocoprineae Sing. of the CIS and Baltic States. Libri botanici 9. Eching: IHW-Verlag

White TJ, Bruns T, Lee S, Taylor J (1990) Amplification and direct sequencing of fungal ribosomal RNA genes for phylogenies. In: Innis MA, Gelfand DH, Sninsky JJ, White TJ (eds) PCR protocols: a guide to methods and applications. Academic Press, San Diego, pp 315-322

Yang ZL (2000) Type studies on agarics described by N. Patouillard (and his co-authors) from Vietnam. Mycotaxon 75:431-476

Ying JZ, Zang M (eds.) (1994) Economic macrofungi from southwestern China. Beijing: Science Press. 399 pp. (in Chinese)

Ying JZ, Wen HA, Zong YC (1994) The Economic macromycetes from western Sichuan. Science, Beijing, in Chinese

Yuan MS, Sun PQ (2007) Atlas of Chinese mushrooms. Sichuan Publishing House of Science and Technology, Chengdu, p 552, in Chinese

Zang M, Li B, Xi JX (1996) Fungi of Hengduan mountains. Science, Beijing, in Chinese 